\title{
THE HANDBOOK OF ENDOCRINE SURGERY
}


This page intentionally left blank 


\section{THE HANDBOOK OF}
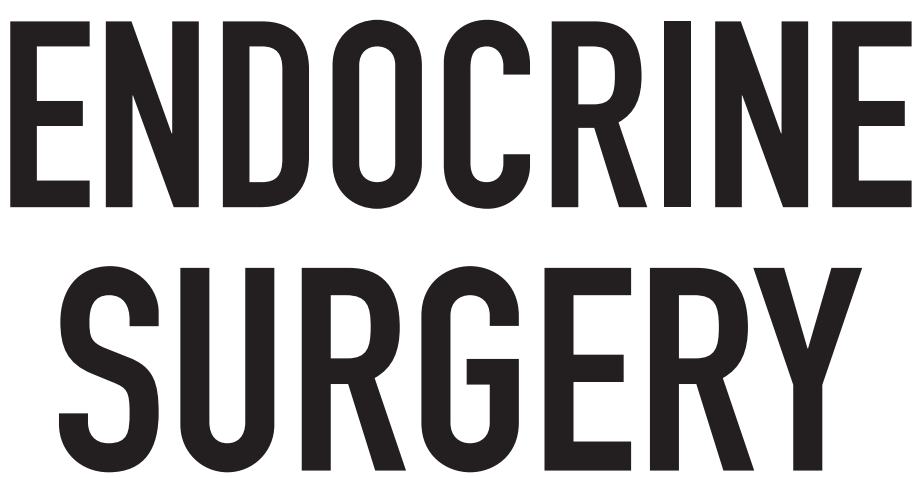

\section{Rebecca S. Sippel Herbert Chen}

University of Wisconsin School of Medicine and Public Health, USA 
Published by

World Scientific Publishing Co. Pte. Ltd.

5 Toh Tuck Link, Singapore 596224

USA office: 27 Warren Street, Suite 401-402, Hackensack, NJ 07601

UK office: 57 Shelton Street, Covent Garden, London WC2H 9HE

\section{British Library Cataloguing-in-Publication Data}

A catalogue record for this book is available from the British Library.

\section{THE HANDBOOK OF ENDOCRINE SURGERY}

Copyright $\left({ }^{\circ} 2012\right.$ by World Scientific Publishing Co. Pte. Ltd.

All rights reserved. This book, or parts thereof, may not be reproduced in any form or by any means, electronic or mechanical, including photocopying, recording or any information storage and retrieval system now known or to be invented, without written permission from the Publisher.

For photocopying of material in this volume, please pay a copying fee through the Copyright Clearance Center, Inc., 222 Rosewood Drive, Danvers, MA 01923, USA. In this case permission to photocopy is not required from the publisher.

ISBN-13 978-981-4293-19-8

ISBN-10 981-4293-19-9

Typeset by Stallion Press

Email: enquiries@stallionpress.com

Printed in Singapore. 
We dedicate this book to our endocrine surgery mentors 
This page intentionally left blank 


\section{Contents}

Contributors $\quad$ xix

Foreword $\quad$ XXXV

Preface $\quad$ xxxvii

I. THYROID 1

A. Evaluation

Chapter I.A.1: Thyroid Evaluation — Laboratory Testing 3

Jennifer L. Poehls and Rebecca S. Sippel

Thyroid Function Tests 3

Thyroid Antibodies $\quad 9$

Thyroid Tumor Markers $\quad 11$

Selected References $\quad 13$

Chapter I.A.2: Thyroid Imaging 15

James E. Wiseman, Lilah F. Morris and

Michael W. Yeh

Introduction $\quad 15$

Ultrasound 16

Computed Tomography (CT) 21

Magnetic Resonance Imaging (MRI) 22

Radionuclide Scanning 22

Positron Emission Tomography (PET) 23 and PET/CT

Selected References 25

Chapter I.A.3: Thyroid Evaluation — FNA 27

Jennifer B. Ogilvie

FNA Technique $\quad 27$

FNA Results and Significance 31 
Recommendations

Selected References

\section{B. Clinical Management}

Chapter I.B.1: Evaluation of a New Thyroid Nodule

Adrienne L. Melck and Sally E. Carty

Epidemiology

History

Physical Examination

Laboratory Investigations

Imaging

Indications for Fine Needle Aspiration Biopsy $\quad 44$

Thyroid Nodule Management after FNAB

Molecular Testing of FNA Specimens

Management of a Benign Thyroid Nodule $\quad 46$

Management of Thyroid Cysts 47

Selected References

Chapter I.B.2: $\quad$ Management of Papillary Thyroid Cancer

Dina M. Elaraj and Cord Sturgeon

Global Treatment Strategy

Controversies in Surgical Management

Management of Nodal Metastases

Radioactive Iodine

TSH Suppression

Long-Term Followup

Management of Recurrent Disease

Selected References

Chapter I.B.3: Management of Medullary Thyroid Cancer

Scott N. Pinchot and Rebecca S. Sippel

Introduction

Management of Sporadic MTC

Management of Hereditary MTC

Genetic Basis of Hereditary MTC

Long-Term Followup

Management of Recurrent Disease

Selected References 
Chapter I.B.4: $\quad$ Management of Follicular and Hurthle Cell Cancer 79 Christopher R. McHenry and Scott M. Wilhelm Introduction 79

Operative Management $\quad 81$

Postoperative Management $\quad 82$

Long Term Followup $\quad 84$

Treatment of Metastatic Disease $\quad 86$

Selected References $\quad 87$

Chapter I.B.5: Management of Aggressive Variants and 89

Anaplastic Thyroid Cancers

Marlon A. Guerrero and Electron Kebebew

Overview $\quad 89$

Tall Cell Variant of Papillary Carcinoma 91

Insular Thyroid Cancer $\quad 93$

Columnar Cell Variant of Papillary Carcinoma 94

Diffuse Sclerosing Variant of Papillary Carcinoma 95

Anaplastic Thyroid Cancer 96

Poorly Differentiated Thyroid Cancer 99

Selected References 100

Chapter I.B.6: Management of Thyroid Lymphomas, 101

Metastatic Lesions and Other Rare Tumors

$N$. Gopalakrishna Iyer and Ashok R. Shaha

Overview

Thyroid Lymphomas 101

Metastatic Disease to the Thyroid Gland 106

Rare Tumors of the Thyroid Gland 107

Selected References $\quad 108$

Chapter I.B.7: Hyperthyroidism 109

Geeta Lal and Sonia L. Sugg

Introduction

Treatment Options $\quad 109$

Specific Conditions 116

Thyroid Storm 122

Selected References $\quad 123$ 
Chapter I.B.8: Management of Complications of Thyroidectomy 125 Jason Long and Peter Angelos

Postoperative Hoarseness

Recurrent Laryngeal Nerve (RLN) Injury

External Branch of the SLN Injury

Selected References

Neck Hematoma

Selected References

Postoperative Hypocalcemia/Hypoparathyroidism

Selected Reference

Management of Injury to the Thoracic Duct or Chyle Leakage

Selected References

Other Nerves at Risk of Injury During Thyroidectomy

Selected References

Chapter I.B.9: Thyroid Hormone Replacement/Adjustment Meei J. Yeung and Jonathan W. Serpell

Thyroid Hormone Replacement/Adjustment

Selected References

\section{PARATHYROID}

\section{A. Evaluation}

Chapter II.A.1: $\quad$ Parathyroid Laboratory Testing

Denise Carneiro-Pla

Introduction

Sporadic Primary Hyperparathyroidism (SPHPT) 147

Differential Diagnosis

Secondary Hyperparathyroidism

Tertiary Hyperparathyroidism

Familial Hyperparathyroidism

Parathyroid Cancer

Bone Mineral Density in Parathyroid Disease 156

Selected References 
Chapter II.A.2: $\quad$ Parathyroid Imaging

Christine S. Landry, Elizabeth G. Grubbs,

Beth S. Edeiken-Monroe, Thinh Vu,

E. Edmund Kim and Nancy D. Perrier

Introduction

Imaging Modalities

Specific Questions for the Endocrine Surgeon

Conclusion

Selected References

\section{B. Clinical Management}

Chapter II.B.1: Clinical Management of Primary

Hyperparathyroidism

Joel T. Adler, Rebecca S. Sippel

and Herbert Chen

Introduction

Indications

Minimally Invasive Parathyroidectomy

Bilateral Exploration

Ectopic Glands

Intraoperative Nerve Monitoring

Conclusions

Selected References

Chapter II.B.2: $\quad$ Secondary Hyperparathyroidism

Mohamed O. Abdelgadir Adam, Patrick H. Pun and John A. Olson, Jr.

Definition

Historical Background

Epidemiology

Pathophysiology

Genetic Etiologies

Clinical Manifestations

Diagnosis

Medical Therapy

Indications for Parathyroidectomy in SHPT 


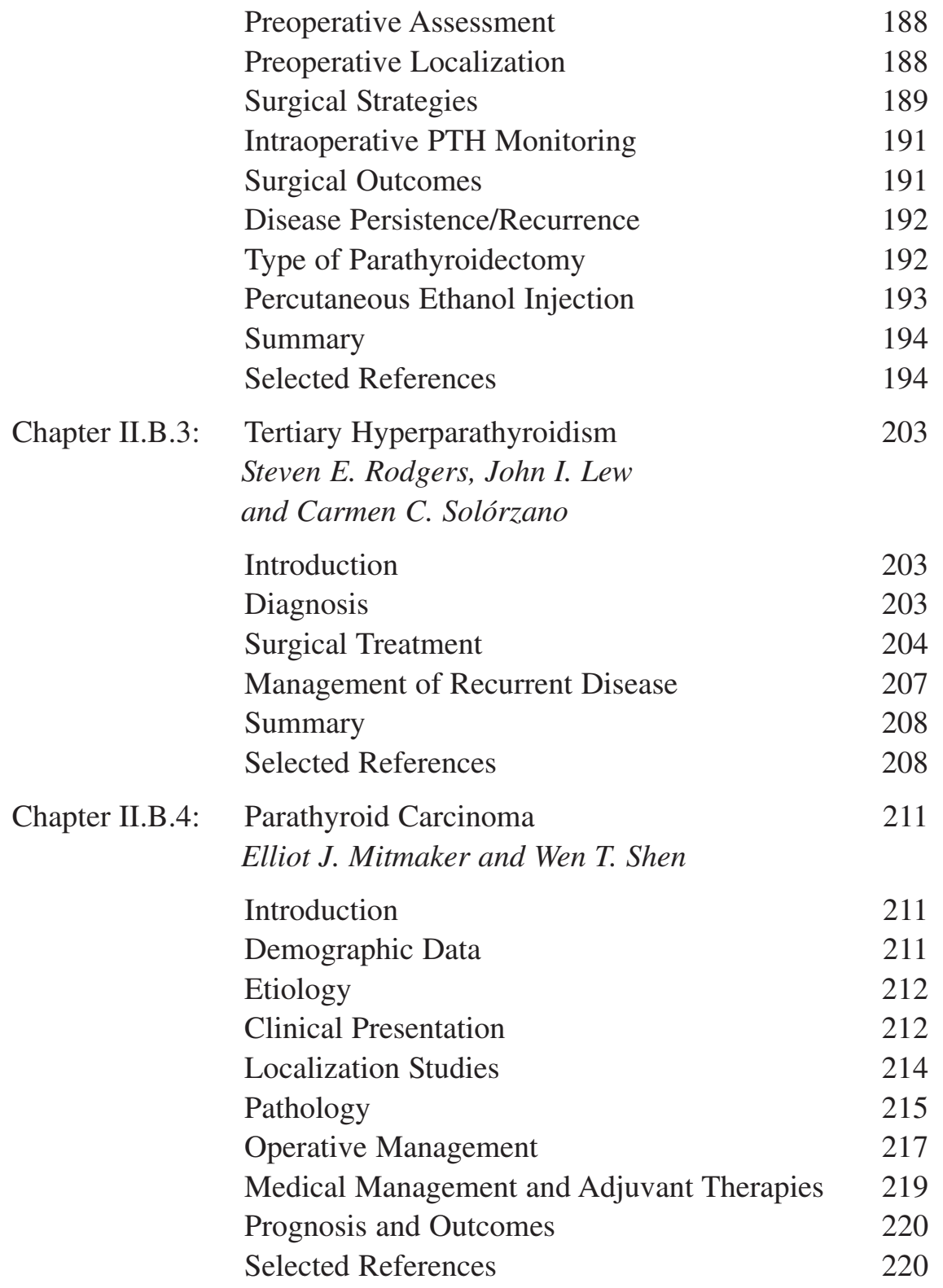


Chapter II.B.5: Hyperparathyroidism in Familial Disease

Charles Tuggle, Julie Ann Sosa

and Robert Udelsman

Overview

Multiple Endocrine Neoplasia 1 (MEN1)

223

Multiple Endocrine Neoplasia 2A (MEN2A)

227

Familial Isolated HPT (FIHPT)

HPT-Jaw Tumor Syndrome (HPT-JT)

Neonatal Severe HPT (NSHPT) and Autosomal

Dominant Mild HPT (ADMH)

Neurofibromatosis Type 1 (NF1)

Family Screening and Genetic Testing 238

Genetic Testing and Counseling 239

Selected References

Chapter II.B.6: Management of Hypercalcemic Crisis

Carrie C. Lubitz and Antonia E. Stephen

Etiology

Definition

Clinical Manifestations

Acute Treatment Options

Selected References

Chapter II.B.7: Postoperative Hypocalcemia

Daniel Levin and Jacob Moalem

Introduction

Thyroid Surgery

Parathyroid Surgery

Reoperative Neck Surgery

Pathophysiology

Postoperative Monitoring

Treatment of Postoperative Hypocalcemia

Summary

Selected References 
Chapter II.B.8: Cryopreservation and Autotransplantation of

Parathyroid Tissue

Jennifer McAllaster and Mark S. Cohen

Introduction

Indications for Parathyroid Autotransplantation 266 and Cryopreservation

Methods for Cryopreservation of Parathyroid Tissue

Long Term Storage, Viability, and Thawing of Cryopreserved Glands

Autotransplantation of Parathyroid Tissue

Post-Operative Management Following

Parathyroid Autotransplantation

Reoperation for Hyperfunctional Autografts

274

Selected References

\section{ADRENAL}

\section{A. Evaluation}

Chapter III.A.1: Adrenal Incidentaloma

Rashmi Roy and James A. Lee

Overview

Laboratory Evaluation

Radiographic Assessment

Selected References

Chapter III.A.2: Cushing's Syndrome: Laboratory and Imaging 287 Evaluation

Geoffrey B. Thompson and William F. Young, Jr.

Introduction

Case Detection for Endogenous

Hypercortisolism: Who Should be Evaluated for Cushing's Syndrome?

Laboratory Evaluation

Subtype Evaluation and Imaging

Selected References 
Chapter III.A.3: Pheochromocytoma

Goswin Y. Meyer-Rochow and Stan B. Sidhu

Introduction

Laboratory Testing

Genetic Testing 306

Imaging Evaluation 309

Selected References

Chapter III.A.4: Evaluation and Diagnosis of

Hyperaldosteronism

Xavier M. Keutgen, Rasa Zarnegar

and Thomas J. Fahey III

Introduction

Diagnosis

Additional Laboratory Tests

Additional Imaging Studies

Selected References

\section{B. Clinical Management}

Chapter III.B.1: Laparoscopic Adrenalectomy

Avital Harari and Quan-Yang Duh

Laparoscopic Transabdominal Approach

Retroperitoneal Laparoscopic Approach

Selected References

Chapter III.B.2: Preoperative and Perioperative Management of Adrenal Lesions

Tricia A. Moo-Young and Richard A. Prinz

Overview

Pheochromocytoma

Hyperaldosteronism

Cushing's Syndrome (Hypercortisolism)

Adrenal Insufficiency

Selected References 
Chapter III.B.3: Adrenal Cortical Cancer

Daniel T. Ruan and Matthew A. Nehs

Diagnosis of Adrenal Cortical Cancer

Prognostic Factors and Determinants of Resectability

Operative Management

Evaluation and Management of Patients with Metastatic Disease

Selected References

\section{ENDOCRINE PANCREAS}

\section{A. Evaluation}

Chapter IV.A.1: Evaluation of Carcinoid Tumors

Katherine Heiden and Mira Milas

Overview

Laboratory Evaluation

Imaging Evaluation

Summary

Selected References

Chapter IV.A.2: Evaluation of Insulinoma

Jui-Yu Chen, Yi-Fang Tsai, Ling-Ming Tseng and Chen-Hsen Lee

Introduction

Laboratory Evaluation

Imaging Evaluation

Selected References

Chapter IV.A.3: Evaluation of Gastrinoma

Adam S. Brinkman and Clifford S. Cho

Introduction

Presentation

Diagnosis

Localization 
Chapter IV.A.4: Evaluation of "Other" Neuroendocrine Tumors of the Pancreas

Rachel Adams Greenup, Tracy S. Wang and Douglas B. Evans

Introduction

Glucagonoma

Clinical Syndrome of Glucagonoma (Think Catabolism!)

Serum Glucagon Levels

Vipoma

Somatostatinoma

PPOMA

Selected References

\section{B. Clinical Management}

Chapter IV.B.1: Clinical Management of Midgut Carcinoid 405 Tumors

Thomas W. T. Ho and Janice L. Pasieka

Overview 405

Midgut Small Bowel Carcinoids

Appendiceal Carcinoids

Goblet Cell Carcinoids

Selected References

Chapter IV.B.2: Clinical Management of Insulinoma

David T. Hughes, Gerard M. Doherty

and Paul G. Gauger

Preoperative Considerations

Operative Planning and Approach

Intraoperative Localization

Operative Technique

Postoperative Management

Special Circumstances

Medical Management

Selected References 
Chapter IV.B.3: Clinical Management of Gastrinoma

Steven K. Libutti

Overview

431

Medical Management of Primary Gastrinomas

440

Selected References

Chapter IV.B.4: Clinical Management of Nonfunctional

443

Neuroendocrine Tumors and Management of Metastatic Disease

Jennifer Rabaglia, Shelby Holt

and Fiemu Nwariaku

Overview

443

Preoperative Evaluation

444

Operative Management of nfPNETS

448

Management of Metastatic and Recurrent

Disease

Selected References

Index 


\section{Contributors}

Mohamed O. Abdelgadir Adam, MD

Resident in Surgery

Department of Surgery

Duke University

DUMC 2945

Durham, NC 27710, USA

Joel T. Adler, MD

Resident, General Surgery

Massachusetts General Hospital

55 Fruit Street, GRB-425

Boston, MA 02114, USA

Peter Angelos, MD, PHD, FACS

Professor and Chief of Endocrine Surgery

University of Chicago

5841 S. Maryland Ave, MC 4052

Chicago, IL 60637, USA

\section{Adam S. Brinkman, MD}

Surgical Resident

University of Wisconsin School of Medicine and Public Health 600 Highland Avenue

Madison, WI 53792, USA 
Denise Carneiro-Pla, MD, fACS

Assistant Professor of Surgery/Endocrine Surgery

Department of Surgery

Medical University of South Carolina

25 Courtenay Dr., Suite 7018

Charleston, SC 29425, USA

Sally E. Carty, MD

Professor of Surgery

University of Pittsburgh

3471 Fifth Ave., Suite 101

Kaufmann Bldg.

Pittsburgh, PA 15213, USA

Herbert Chen, MD, FACS

Professor, Chairman of General Surgery

University of Wisconsin School of Medicine and Public Health K3/703, Clinical Science Center

600 Highland Avenue

Madison, WI 53705, USA

\section{Jui-Yu Chen, MD}

Attending Physician and Instructor

National Yang-Ming University

Department of Surgery, Division of General Surgery

Taipei Veterans General Hospital

No. 201, Sec. 2, Shipai Rd., Beitou District

Taipei City, Taiwan 11217, R.O.C.

Clifford S. Cho, MD

Assistant Professor

University of Wisconsin School of Medicine and Public Health K4/752, Clinical Science Center

600 Highland Avenue

Madison, WI 53792, USA 
Mark S. Cohen, MD, FACS

Associate Professor of Surgery and Pharmacology

Toxicology and Therapeutics

Chief of Endocrine Surgery, Vice Chair for Research and Director

Surgical Simulation and Skills Laboratory

University of Kansas Medical Center

3901 Rainbow Boulevard

Mailstop 2005, Room 4008 Murphy Building

Kansas City, KS 66160, USA

Gerard M. Doherty, MD

Norman W. Thompson Professor of Surgery

University of Michigan Medical School

University of Michigan Hospital

1500 East Medical Center Drive

Taubman Center 2920B

Ann Arbor, MI 48109-0331, USA

Quan-Yang Duh, MD

Professor of Surgery

University of California, San Francisco and

VA Medical Center, San Francisco

4150 Clement Street

San Francisco, CA 94121, USA

Beth S. Edeiken-Monroe, MD

Professor

MD Anderson Cancer Center

1500 Holcombe Blvd.

Houston, TX 77030, USA

Dina M. Elaraj, MD, FACS

Assistant Professor

Section of Endocrine Surgery

Department of Surgery

Northwestern University

676 North St. Clair Street, Suite 650

Chicago, Il 60611, USA 


\section{Douglas B. Evans, MD}

Chairman, Department of Surgery

Donald C. Ausman Family Foundation Professor of Surgery

Medical College of Wisconsin

9200 W. Wisconsin Avenue

Milwaukee, WI 53226, USA

Thomas J. Fahey III, MD, FACS

Professor of Surgery

Weill Cornell Medical College

525 East 68th Street, Room A-1027

New York, NY 10021, USA

Paul G. Gauger, MD

William J. Fry Professor of Surgery

University of Michigan Medical School

University of Michigan Hospital

1500 East Medical Center Drive

Taubman Center 2920D

Ann Arbor, MI 48109-0331, USA

Rachel Adams Greenup, MD, MPH

Chief Resident, General Surgery

Medical College of Wisconsin

9200 W. Wisconsin Avenue

Milwaukee, WI 53226, USA

Elizabeth G. Grubbs, MD

Assistant Professor

MD Anderson Cancer Center

1400 Hermann Pressler Drive, Unit 1484

Houston, TX 77030, USA

Marlon A. Guerrero, MD

Assistant Professor

University of Arizona

Arizona Health Science Center

1501 N. Campbell Ave.

Tucson, AZ 85724-5131, USA 


\section{Avital Harari, MD}

Assistant Professor of Surgery

University of California, Los Angeles

10833 Le Conte Ave, Suite 72-232 CHS

Los Angeles, CA 90095, USA

\section{Katherine Heiden, MD}

Assistant Professor of Surgery

Rush University Medical Center

1725 W. Harrison, Suite 818

Chicago, IL 60612, USA

\section{Thomas W. T. Ho, MD}

Resident-Surgical Oncology

Department of Surgery/North Tower

University of Calgary

1403 29th Street NW, Calgary

Alberta, Canada T2N2T9

\section{Shelby Holt, MD}

Associate Professor of Surgery

University of Texas Southwestern Medical Center

5323 Harry Hines Boulevard

Dallas, TX 75390-9156, USA

David T. Hughes, MD

Assistant Professor of Surgery

Albert Einstein College of Medicine

Montefiore Medical Center

1400 Bainbridge Ave.

Bronx, NY 10467, USA

N. Gopalakrishna Iyer, MBBS, PHD, FRCS

Consultant Head and Neck Surgeon

National Cancer Centre Singapore

11 Hospital Drive, Singapore 169610 


\section{Electron Kebebew, MD, FACS}

Head Endocrine Oncology, Senior Investigator

National Cancer Institute

10 Center Drive

Bethesda, MD 20892-1201, USA

Xavier M. Keutgen, MD

Surgery Resident

Weill Cornell Medical College

525 East 68th Street, Room A-1027

New York, NY 10021, USA

\section{E. Edmund Kim, MD}

Professor

MD Anderson Cancer Center

1515 Holcombe Blvd.

Houston, TX 77030, USA

Geeta Lal, MD

Assistant Professor

University of Iowa Hospitals and Clinics

200 Hawkins Drive, 4641 JCP

Iowa City, IA 52242, USA

Christine S. Landry, MD

Surgical Oncology Fellow

MD Anderson Cancer Center

1400 Hermann Pressler Drive, Unit 1484

Houston, TX 77030, USA

Chen-Hsen Lee, MD, FACS

Dean of Medicine, Professor, School of Medicine

National Yang-Ming University

Department of Surgery, Division of General Surgery

Taipei Veterans General Hospital

No. 201, Sec. 2, Shipai Rd., Beitou District

Taipei City, Taiwan 11217, R.O.C. 
James A. Lee, MD

Chief of Endocrine Surgery

New York Presbyterian Hospital-Columbia University

Columbia University Medical Center

Herbert Irving Pavilion Room 819

161 Fort Washington Avenue

New York, NY 10032, USA

Daniel Levin, MD

Surgical Resident

University of Rochester Medical Center

601 Elmwood Ave, BOX SURG

Rochester, NY 14642, USA

John I. Lew, MD

Assistant Professor of Surgery

University of Miami School of Medicine

1120 NW 14th Street (M875)

Miami, FL 33136, USA

Steven K. Libutti, MD, FACS

Vice Chairman of Surgery

Albert Einstein College of Medicine and Montefiore Medical Center

3400 Bainbridge Ave, MAP4

Bronx, NY 10467, USA

Jason Long, MD

Resident in Surgery

University of Chicago

5841 S. Maryland Ave, MC 4052

Chicago, IL 60637, USA 
Carrie C. Lubitz, MD

Instructor in Surgery

Harvard Medical School

Massachusetts General Hospital

55 Fruit Street, Yawkey 7B

Boston, MA 02114, USA

Jennifer McAllaster, MD

Chief Resident, Department of Surgery

University of Kansas Medical Center

3901 Rainbow Boulevard

Mailstop 2005, Room 4008 Murphy Building

Kansas City, KS 66160, USA

Christopher R. McHenry, MD

Vice Chairman, Department of Surgery

MetroHealth Medical Center

Case Western Reserve University

2500 MetroHealth Drive

Cleveland, OH 44109-1998, USA

Adrienne L. Melck, MD, MPH

Clinical Instructor in Surgery

University of British Columbia

Rm. C303 - 1081 Burrard Street

St. Paul's Hospital Department of Surgery

Vancouver, BC, V6Z 1Y6, Canada

Goswin Y. Meyer-Rochow, MB, CHB, FRACS, PhD

Waikato Clinical School

University of Auckland

Waikato Hospital

Private Bag 3200

Hamilton 3240, New Zealand 


\section{Mira Milas, MD}

Associate Professor of Surgery

Cleveland Clinic

9500 Euclid Ave

Endocrine Surgery F20

Cleveland, $\mathrm{OH} 44195$, USA

Elliot J. Mitmaker, MD, MSC, FRCSC

Endocrine Surgery Fellow

University of California, San Francisco

1600 Divisadero Street, C-347

Mount Zion Hospital, Hellman Building

San Francisco, CA 94143, USA

Jacob Moalem, MD

Assistant Professor, Endocrine Surgery

University of Rochester Medical Center

601 Elmwood Ave, BOX SURG

Rochester, NY 14642, USA

\section{Tricia A. Moo-Young, MD}

Staff Endocrine Surgeon

Northshore University HealthSystems

2650 Ridge Avenue

Walgreens Building, Suite 2507

Evanston, IL 60201, USA

\section{Lilah F. Morris, MD}

Longmire Administrative Chief Resident in General Surgery

Endocrine Surgical Unit, Division of General Surgery

David Geffen School of Medicine at UCLA

10833 Le Conte Ave., 72-229 CHS

Los Angeles, CA 90095, USA 


\section{Matthew A. Nehs, MD}

Clinical Fellow in Surgery

Harvard Medical School

75 Francis Street, ASBII

Boston, MA 02115, USA

\section{Fiemu Nwariaku, MD}

Associate Dean for Global Health

Associate Professor of Surgery

University of Texas Southwestern Medical Center

5323 Harry Hines Boulevard

Dallas, TX 75390-9156, USA

Jennifer B. Ogilvie, MD, FACS

Assistant Professor of Surgery

New York University Langone Medical Center

530 First Avenue, Schwartz Health Care Center, 6H

New York, NY 10016, USA

John A. Olson, Jr., MD, PhD

Associate Professor of Surgery

Chief, Section of Endocrine and Oncologic Surgery

Department of Surgery

Duke University

DUMC 2945

Durham, NC 27710, USA

\section{Janice L. Pasieka, MD, FRCSC, FACS}

Clinical Professor of Surgery and Oncology

Department of Surgery/North Tower

University of Calgary

1403 29th Street NW, Calgary

Alberta, Canada T2N2T9 
Nancy D. Perrier, MD

Professor

MD Anderson Cancer Center

1400 Hermann Pressler Drive, Unit 1484

Houston, TX 77030, USA

Scott N. Pinchot, MD

General Surgery Resident

University of Wisconsin-Madison

H4/7, Clinical Science Center

600 Highland Avenue

Madison, WI 53792, USA

Jennifer L. Poehls, MD

Department of Medicine

Division of Endocrinology, Diabetes and Metabolism

University of Wisconsin

2226 UW Health West Clinic

451 Junction Road

Madison, WI 53717, USA

\section{Richard A. Prinz, MD}

Vice-Chair of Surgery, Staff Endocrine Surgeon

Northshore University HealthSystems

2650 Ridge Avenue

Walgreens Building, Suite 2507

Evanston, IL 60201, USA

Patrick H. Pun, MD, MHS

Assistant Professor of Medicine

Department of Medicine (Nephrology)

Duke University Medical Center

DUMC 2747

Durham, NC 27710, USA 


\section{Jennifer Rabaglia, MD}

Assistant Professor of Surgery

University of Texas Southwestern Medical Center

5323 Harry Hines Boulevard

Dallas, TX 75390-9156, USA

Steven E. Rodgers, MD, PhD

Assistant Professor of Surgery

University of Miami School of Medicine

1120 NW 14th Street (C232)

Miami, FL 33136, USA

Rashmi Roy, MD

Endocrine Surgery Fellow

Department of Endocrine Surgery

Johns Hopkins University School of Medicine

Johns Hopkins Hospital

600 N. Wolfe Street

Blalock 6th Floor, Room 606

Baltimore, MD 21287, USA

Daniel T. Ruan, MD

Instructor in Surgery

Harvard Medical School

75 Francis Street, ASBII

Boston, MA 02115, USA

Jonathan W. Serpell, MBBS, MD, FRACS, FACS

Professor, Monash University Endocrine Surgery Unit

Alfred Hospital, Melbourne, Victoria, Australia

Department of General Surgery, Level 6 Centre Block

Alfred Hospital, Commercial Road, Prahran 3181

Melbourne, Victoria, Australia

Ashok R. Shaha, MD, FACS

Professor of Surgery

Jatin P Shah Chair in Head and Neck Surgery

Memorial Sloan Kettering Cancer Center

1275 York Avenue

New York, NY 10065, USA 
Wen T. Shen, MD, MA

Assistant Professor

University of California, San Francisco

1600 Divisadero Street, C-347

Mount Zion Hospital, Hellman Building

San Francisco, CA 94143, USA

Stan B. Sidhu, MD, BS, PhD, FRACS

Associate Professor, Endocrine Surgical Unit

University of Sydney

202/69 Christie St

St Leonards, NSW 2065, Australia

Rebecca S. Sippel, MD, FACS

Assistant Professor, Chief of Endocrine Surgery

Department of Surgery

University of Wisconsin School of Medicine and Public Health

K3/704, Clinical Science Center

600 Highland Avenue

Madison, WI 53792, USA

Carmen C. Solórzano, MD

Associate Professor of Surgery

Vanderbilt University School of Medicine

597 PRB, 2220 Pierce Ave

Nashville, TN 37232, USA

Julie Ann Sosa, MD, MA

Associate Professor of Surgery

(Surgical Oncology and Endocrine Surgery)

Department of Surgery

Yale University School of Medicine

TMP 204, 333 Cedar Street

New Haven, CT 06520-8062, USA

Antonia E. Stephen, MD

Instructor in Surgery

Harvard Medical School

Massachusetts General Hospital

55 Fruit Street, Yawkey 7B

Boston, MA 02114, USA 
Cord Sturgeon, MD, MS, FACS

Associate Professor

Director of Endocrine Surgery

Department of Surgery

Northwestern University

676 North St. Clair Street, Suite 650

Chicago, I1 60611, USA

Sonia L. Sugg, MD

Associate Professor

University of Iowa Hospitals and Clinics

200 Hawkins Drive, 4646 JCP

Iowa City, IA 52242, USA

Geoffrey B. Thompson, MD

Chief, Endocrine Surgery

Mayo Clinic

2001 st St SW

Rochester, MN 55905, USA

Yi-Fang Tsai, MD

Attending Physician and Instructor

National Yang-Ming University

Department of Surgery, Division of General Surgery

Taipei Veterans General Hospital

No. 201, Sec. 2, Shipai Rd., Beitou District

Taipei City, Taiwan 11217, R.O.C.

\section{Ling-Ming Tseng, MD}

Attending Physician and Assistant Professor

National Yang-Ming University

Department of Surgery, Division of General Surgery

Taipei Veterans General Hospital

No. 201, Sec. 2, Shipai Rd., Beitou District

Taipei City, Taiwan 11217, R.O.C. 


\section{Charles Tuggle, BS}

Department of Surgery

Yale University School of Medicine

PO Box 208062, 333 Cedar Street

New Haven, CT 06520-8062, USA

Robert Udelsman, MD, MBA

William H. Carmalt Professor of Surgery and Chair

Department of Surgery

Yale University School of Medicine

Surgeon-in-Chief, Yale-New Haven Hospital

FMB 102, 310 Cedar Street

New Haven, CT 06510, USA

Thinh Vu, MD

Assistant Professor

MD Anderson Cancer Center

1515 Holcombe Blvd.

Houston, TX 77030, USA

Tracy S. Wang, MD, MPH

Assistant Professor, Division of Surgical Oncology

Medical College of Wisconsin

9200 W. Wisconsin Avenue

Milwaukee, WI 53226, USA

Scott M. Wilhelm, MD

University Hospitals of Cleveland

11100 Euclid Avenue

Cleveland, OH 44106, USA

James E. Wiseman, MD

Earl Gales Research Fellow in Endocrine Surgery

Endocrine Surgical Unit, Division of General Surgery

David Geffen School of Medicine at UCLA

10833 Le Conte Ave., 72-229 CHS

Los Angeles, CA 90095, USA 
Michael W. Yeh, MD

Assistant Professor of Surgery and Medicine (Endocrinology)

Endocrine Surgical Unit, Division of General Surgery

David Geffen School of Medicine at UCLA

10833 Le Conte Ave., 72-228 CHS

Los Angeles, CA 90095, USA

Meei J. Yeung, MBBs, FRACS

Monash University Endocrine Surgery Unit

Alfred Hospital, Melbourne, Victoria, Australia

Suite 6, 243 New Street, Brighton 3186

Melbourne, Victoria, Australia

William F. Young, Jr., MD, MSC

Vice Chair, Division of Endocrinology

Mayo Clinic

200 1st St SW

Rochester, MN 55905, USA

Rasa Zarnegar, MD, FACS

Assistant Professor of Surgery

Weill Cornell Medical College

525 East 68th Street, Room A-1027

New York, NY 10021, USA 


\section{Foreword}

I am honored to be invited to write the foreword for this outstanding and up-to-date book titled Handbook of Endocrine Surgery and edited by Rebecca Sippel, MD and Herb Chen MD. The editors, who are expert endocrine surgeons at the University of Wisconsin, Madison, have assembled a talented group of endocrine surgeons from the USA and Australasia as authors. This very practical and clinically oriented book provides valuable information for surgeons who care for patients with endocrine surgical problems. The authors present concise information regarding the preoperative evaluation, surgical technique, approach and decisions on how to avoid complications, and how to manage postoperative problems when they occur.

Endocrine surgery is a rapidly evolving specialty of general surgery and head and neck surgery. Recent publications document that patients operated upon by surgeons who perform more endocrine surgical operations have fewer complications than when the same operations are performed by less experienced surgeons. Most major medical centers in the USA and worldwide now have endocrine surgical teams that work closely with endocrinologists, nuclear medicine physicians, radiation therapists, cytologists, pathologists and basic scientists. National and International Endocrine Surgical meetings have been established and are growing rapidly.

We must be thankful for the contributions to endocrine surgery by Drs. Theodor Kocher, William Halsted, Harvey Cushing, George Crile, Frank H. Lahey. Charles Mayo, Oliver Cope, Selwyn Taylor, Richard Wellbourn, Per-Ola Granberg, Leon Goldman, Oliver H. Beahrs, Norman Thompson, Charles Proye, Hans Roeher, Thom Reeves, Samuel A. Wells, 
Edwin Kaplan and many other surgeons who have helped to improve the care of patients with endocrine surgical disorders. This book by Drs. Sippel and Chen helps follow this rich tradition.

Orlo H. Clark, MD

Professor of Surgery

University of California San Francisco 


\section{Preface}

While endocrine surgery is a field that demands meticulous operative technique and close attention to detail, it requires just as much if not more in the preoperative and postoperative management of patients. As endocrine surgeons we are not merely technicians removing a thyroid or a parathyroid, but physicians that are curing diseases of the endocrine system through surgery. What separates us from other surgeons that may do the same technical operation is that we understand the diseases we are operating on and how to determine who needs an operation, what operation should be done, and how to best care for the patient before and afterwards.

Much of what we know about the practice of endocrine surgery isn't learned from reading journal articles or book chapters; it was learned from our mentors, who helped to train us in both the art and science of endocrine surgery. It is the clinical pearls that our mentors taught us of "how I do it" that is at the essence of this book.

Residents and fellows are taught what tests to order and what is in the differential diagnosis, but when it comes down to interpreting those tests or figuring out how to actually rule out those other conditions in the differential diagnosis they often struggle to find a reference that could help in the actual day to day clinical world. They may know that a patient with suspected Cushing's syndrome needs to get a dexamethasone suppression test, but don't really know what that means. When do you give the steroids, when do you check the labs, how do you interpret the results, do you need to stop any medications? There are plenty of books and references that will tell you the correct test to order, but few that tell you exactly how to do it or how to interpret it. Hence the goal of this book is to be a reference that can answer those questions. This book is designed to be a very practical and clinical relevant reference that can guide the 
practicing surgeon through the work up and management of patients with surgical endocrine diseases.

The book is divided into four main sections focusing on Thyroid, Parathyroid, Adrenal, and Endocrine Pancreas. Each section is divided into two parts with the first part focusing on diagnosis and the second part focusing on clinical management. The authors of this book are leaders in endocrine surgery both past, present, and future. They share the wisdom of their experience and knowledge, as well as their mentors, and help to shape your understanding of the diseases that they treat. The authors have incorporated the latest tests and techniques and shared their practical experience of "how they do it."

We are grateful to the many contributors to this text. This book represents the efforts of many people whom we consider friends and colleagues as well as leaders in the field. They have put forth a great effort into their contributions and it is our hope that you will appreciate their knowledge and effort and find this text an invaluable resource in your day to day practice. 